\title{
VIRTUAL TOUR ENVIRONMENT OF CUBA'S NATIONAL SCHOOL OF ART
}

\author{
R. K. Napolitano ${ }^{\mathrm{a} *}$ I. P. Douglas ${ }^{\mathrm{a}}$, M. E. Garlock ${ }^{\mathrm{a}}$, B. Glisic ${ }^{\mathrm{a}}$ \\ ${ }^{a}$ Princeton University, Department of Civil and Environmental Engineering, \\ 59 Olden Street, Princeton, NJ - (rkn2, idouglas, mgarlock, bglisic)@ princeton.edu.
}

Commission WG II

KEY WORDS: Virtual tour, Spherical panorama, Initial documentation, Heritage structure, Cuba, National Ballet School

\begin{abstract}
:
Innovative technologies have enabled new opportunities for collecting, analyzing, and sharing information about cultural heritage sites. Through a combination of two of these technologies, spherical imaging and virtual tour environment, we preliminarily documented one of Cuba's National Schools of Art, the National Ballet School.The Ballet School is one of the five National Art Schools built in Havana, Cuba after the revolution. Due to changes in the political climate, construction was halted on the schools before completion. The Ballet School in particular was partially completed but never used for the intended purpose. Over the years, the surrounding vegetation and environment have started to overtake the buildings; damages such as missing bricks, corroded rebar, and broken tie bars can be seen. We created a virtual tour through the Ballet School which highlights key satellite classrooms and the main domed performance spaces. Scenes of the virtual tour were captured utilizing the Ricoh Theta S spherical imaging camera and processed with Kolor Panotour virtual environment software. Different forms of data can be included in this environment in order to provide a user with pertinent information. Image galleries, hyperlinks to websites, videos, PDFs, and links to databases can be embedded within the scene and interacted with by a user. By including this information within the virtual tour, a user can better understand how the site was constructed as well as the existing types of damage. The results of this work are recommendations for how a site can be preliminarily documented and information can be initially organized and shared.
\end{abstract}

\section{INTRODUCTION}

The National Ballet School is one of five National Art Schools built in Cuba following the revolution. Since the iconic structures which comprise the National Ballet School have been studied in depth from a aesthetic and architectural perspective, and yet not from an engineering perspective, the goal of the research was to understand the structural system and perform rigorous analysis of the dome (Fig. 1 [3])

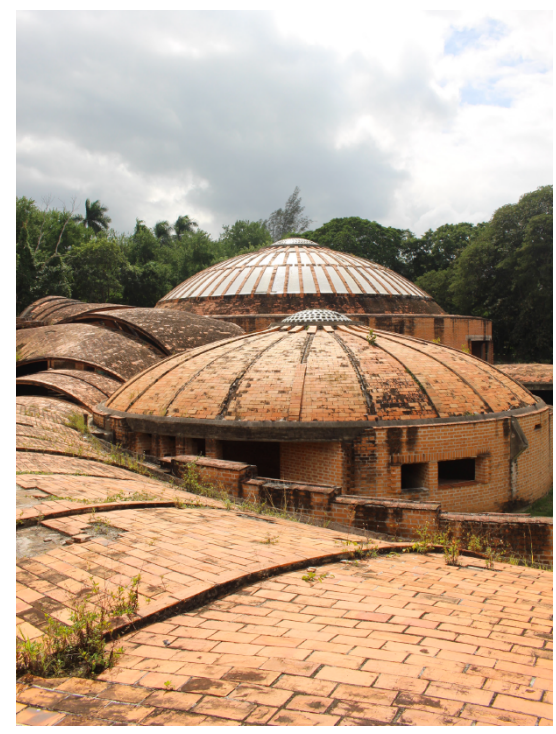

Figure 1. Current state of Cuba's National Ballet School with main dome depicted in the background
To analyze the main dome, initial documentation was completed that encompassed taking key measurements, attaining primary sources concerning the construction, noting visible damage to the structure, and documenting what the buildings look like. The buildings were documented, both inside and the outside, using an approach called virtual tours and informational modeling (VT/IM). For this project, photogrammetry and laser scanning were not used to create a $3 \mathrm{D}$ model due to specific project requirements, time constraints, and budget. This decision was based on criteria set out by Letellier in Recording, Documentation, and Information Management for Conservation of Heritage Places [7]. In this resource, how to define the scope of a heritage recording is outlined and broken down into the questions depicted in Fig. 2 [7].

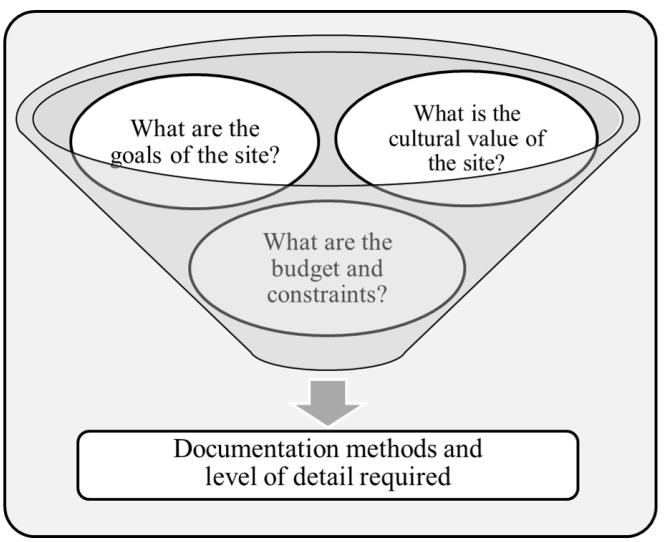

Figure 2. Selection criteria for appropriate documentation methods, based on research done by Letellier.

${ }^{*}$ Corresponding author 


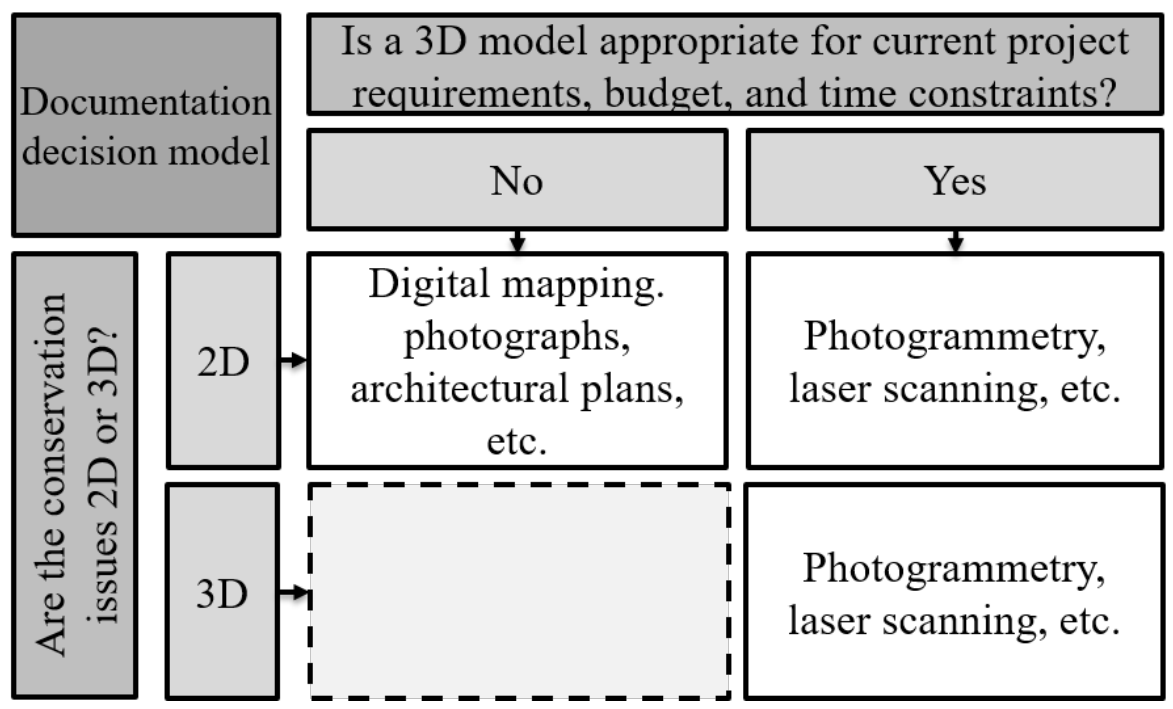

Figure 3. Gap in current methods for efficient documentation of conservation challenges

Currently, many virtual tours of historic structures exist for tourism and education purposes. One such project is Colonial Williamsburg which is an interactive map [13]. This project includes two options: 1) user-defined path and 2) prescribed path. A user-defined path enables a user to choose the buildings that interest them and virtually walk around the grounds. On a prescribed path a user is led through the grounds in a predefined order. Another example of a virtual tour is the Mount Vernon mansion [9]. The Mount Vernon Mansion links $360^{\circ}$ spherical panoramas together to create a user-defined tour environment. While some virtual tour projects use $360^{\circ}$ panoramas and others do not, we have chosen to use $360^{\circ}$ spherical panoramas to depict the environment in Cuba in order to fully capture the domed ceilings and vaults of the buildings.

While, virtual tours have been implemented on historic sites for documenting and disseminating information, VT/IM has yet to be applied in building conservation and analysis. In this initial study, we provide a method for future implementation of VT/IM and test it on a case study. This method is only appropriate for conservation projects where preliminary documentation of 3D conservation issues is essential, but a $3 \mathrm{D}$ model is not.

\section{GAP IN CURRENT METHODS}

Current methods for documenting the buildings include 2D methods such as digital mapping, or 3D methods such as photogrammetry and laser scanning. However, if these methods are applied incorrectly, they can be ineffective and inefficient in terms of time, money, data management, and communication. For example if a conservation challenge on a building is on two different regions that cannot be pictured together, $2 \mathrm{D}$ methods can lead to miscommunications and flawed analysis of the building. Additionally, if a conservation challenge is isolated to only the facade of a building and a 3D model is not within the scope of the project goals, using 3D approaches can be costly in terms of time, money, and data management. The gap in current methods for documenting buildings can be seen in Fig. 3.

As illustrated in Fig. 3, if the conservation challenge is 3D, yet a $3 \mathrm{D}$ model is not appropriate for the current project requirements, budget, and time constraints, there is not an established method for analytical documentation. Previous studies in construction management and building documentation outline approaches combining Virtual Reality (VR) and Information Modeling (IM) [1, 2, 4-6, 12]. In those studies, VR refers to environments including 3D models or virtual tours (VT) where VT is an immersive environment comprised of spherical panoramas. IM refers to the inclusion of relevant data such as reports or maintenance logs. Previously, studies suggested combining IM and VR to document buildings [4]. However, no VT/IM method currently exists for building conservation and analysis.

\section{CASE STUDY}

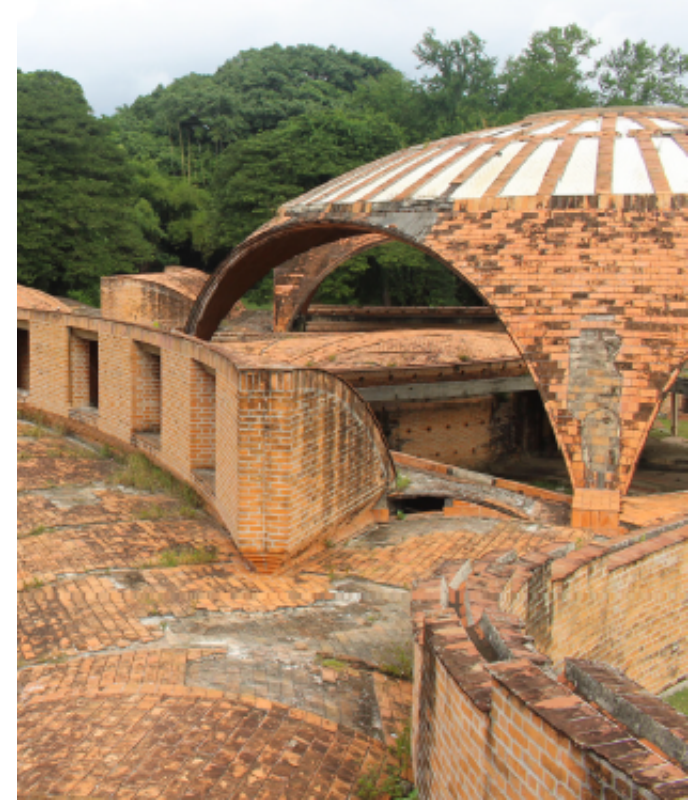

Figure 4. National Ballet School, Havana, Cuba: classroom.

The VT/IM method was applied to the National Ballet School. One of the three main classrooms can be seen in Fig. 4 [8]. Initiated under the reign of Fidel Castro, this project was seen as a chance for Cuba to establish its own internationally acclaimed centers for arts and culture. In 1959, it was decided that five 
schools would be built for Plastic Arts, Modern Dance, Ballet, Music, and Dramatic Arts. Since many established Cuban architects had fled after the revolution, there was a surge of younger designers who could be creative with the design of these schools. Architect Richardo Porro was selected to head a team of architects including two Italian nationals, Roberto Gottardi and Vittorio Garatti.

Work to build these structures commenced in 1961, a two short years after the conception of the idea, and the schools were simultaneously built and designed. Due to the U.S. embargo however, many essential construction materials, specifically steel, were available in limited quantities. This led to many creative structural solutions within the Art Schools which make them interesting to an engineering audience. Within a four year period (1961-1965) the Art Schools were designed and partially constructed. Due to changes in the political climate, construction was halted before completion. The Ballet School in particular was $90 \%$ complete but never used for its intended purpose. Over the years it has been subjected to environmental and anthropogenic abuse which includes floods, looting, and graffiti. In 2003, the United Nations Educational, Science, and Cultural Organization (UNESCO) added the Art Schools to a tentative list of World Heritage Sites [11]. This decision was significant since it was the first time UNESCO had listed a structure for which the architects were still alive. Additionally the National Art Schools are on the 2000 and 2016 World Monuments Watch list [10].

A plan view of the campus can be seen in Fig. 5 which has been annotated to denote where spherical panoramas for the virtual tour were taken; additionally, an elevation section can be seen in Fig. 6 [8].

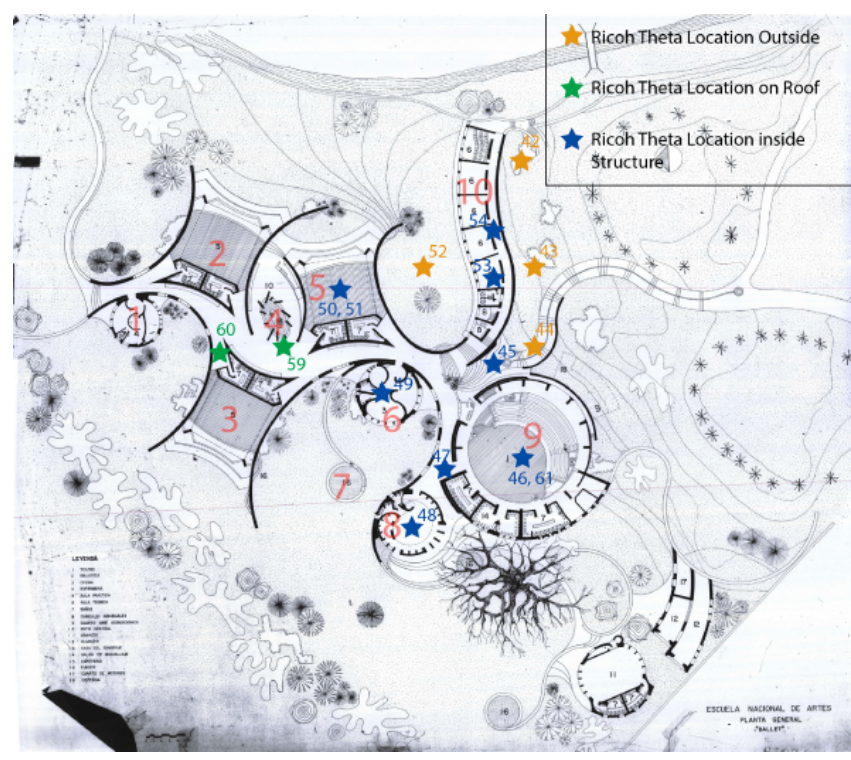

Figure 5. Plan drawing of National Ballet School. The annotations reflect where spherical panoramas for the virtual tour were taken.

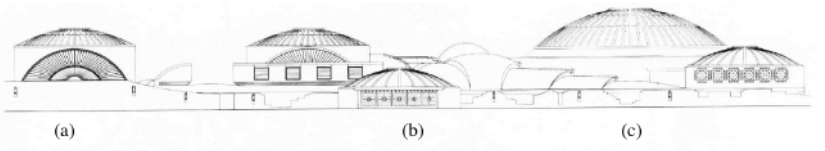

Figure 6. Elevation drawing of National Ballet School.
Since the Ballet School was intended to be a symbol of freedom and of the future, architect Vittorio Garatti was inspired by a dancer when he designed the complex. Laid out in an "S" shape, Garatti's intention was for the core of the schools to resemble a spine in order to embody motion and dynamism. The complex consists of a series of domes which are connected by a Guastavino vaulted walkway.

\subsection{Creating the virtual tour}

We used the Ricoh Theta S camera to capture the spherical panoramas for the virtual tour. A spherical panorama captures not only $360^{\circ}$ view perpendicular to the camera lens, but also the floor and ceiling of the building being documented. This feature was crucial for the images taken inside the buildings so that we could document and understand the structural system of the domes and vaults. This camera choice was based on the camera's capacity to automatically stitch the panoramas together which expedited the process. The virtual tour environment was created using Kolor Panotour Pro. This software enabled us to stitch together adjacent panoramas so a user can virtually walk around the building.

\section{RESULTS}

The result of this work is an interactive virtual tour of Cuba's National Ballet school which is compatible with computers, tablets, and other mobile devices. Composed of 14 spherical panoramas, 96 hotspots, and 40 links, this virtual tour presents conservation and structural issues around the campus of the Ballet School in an interactive manner. The interface for the tour in Fig. 7 illustrates the methods of navigating the virtual environment. A user can chose to move through the tour using three methods: (1) an interactive geographic map, (2) a drop down list of panoramas, (3) "hotspots" visible inside the environment. A "hotspot" is an on-click conditional which means that when a user clicks on a hotspot in the virtual tour, it performs a prescribed action. In the virtual tour of the Ballet School, a user can click between adjacent panoramas to move in a natural manner around the grounds.
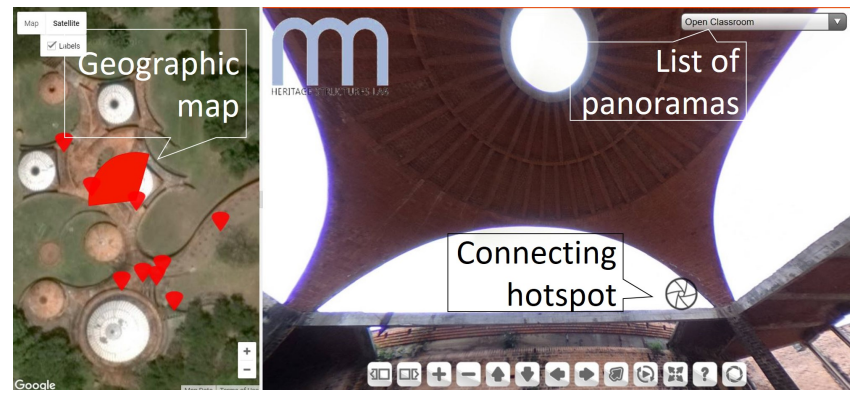

Figure 7. Navigational interface for VT/IM environment.

In addition to this capability, the hotspots enable a user to input information about the state of a the structure to facilitate informational modeling. As can be seen in Fig. 8, there are visual cues inserted into the VT/IM environment to signal to a user when there is information available. When a user clicks on the camera icon, a specific image is brought into the viewer. In this particular scene, we are highlighting the structural system and the material choice to a viewer. If a viewer clicks on the camera icon, they see an image of the tiled edge of the quadripartite dome. If a user next clicks on the information icon, a text box with information is displayed on the viewer. This enables disparate groups 
working on a project to communicate specific information about specific locations on a building. Understanding where material samples come from and where particular cracks are on a building, informs the subsequent structural analysis which can aid in the preservation of historic structures. Additionally, through similar hotspots, a user can interact with architectural plans, conservation reports, databases about previous interventions, and other types of information. By providing all of the relevant information about a structure, groups involved in the various stages of conservation can communicate efficiently and access the data they need to facilitate decision making. A video sample of the VT/IM in use on this structure can be found at the following link:

https://vimeo.com/219730868
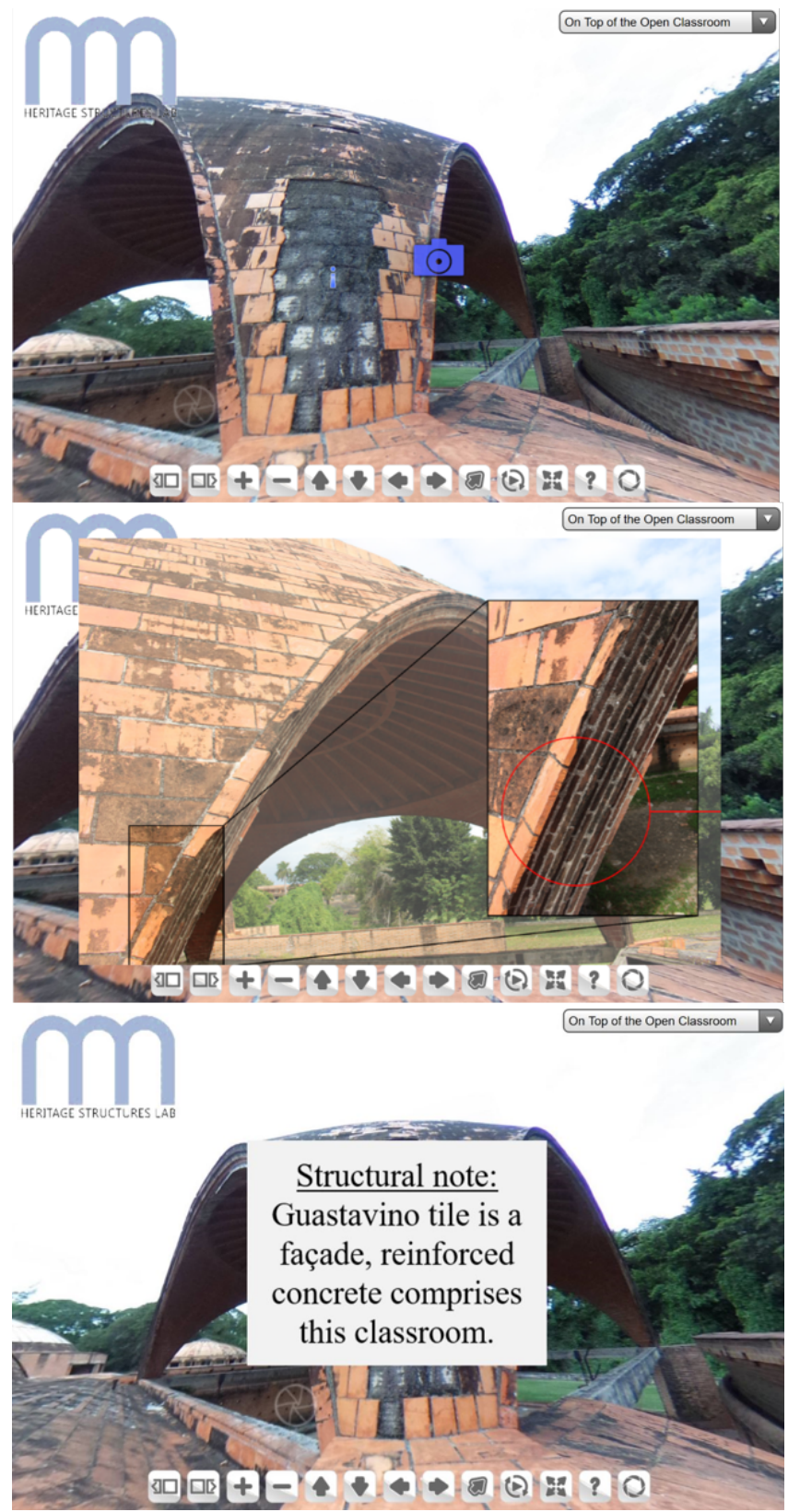

Figure 8. Illustration of hotspots in VT/IM environment. The top figure depicts the icons in the environment; the subsequent figures illustrate hotspot capabilites.

\subsection{Primary documents}

In addition to documenting the structure as it stands today, we were interested in documenting any existing primary sources concerning the construction of the buildings. Work was done to digitize the construction notes and photographs of the main builder, Jose Mosquera (Fig. 9 [3]) These photographs were not publically available before this work and have brought to light new structural understandings about these buildings. For instance, it was commonly thought prior to this research that the classrooms were constructed using a technique called Guastavino vaulting. However after first-hand investigation of the buildings themselves and the construction documents it is clear that the classrooms are built of concrete and steel reinforcements. This knowledge, which was missing prior to this work, is crucial in understanding how best to analyze and preserve these structures. By combining this data with the primary construction images in the VT/IM we can facilitate communication between remote groups analyzing the structure and ensure that the true structural form is understood.

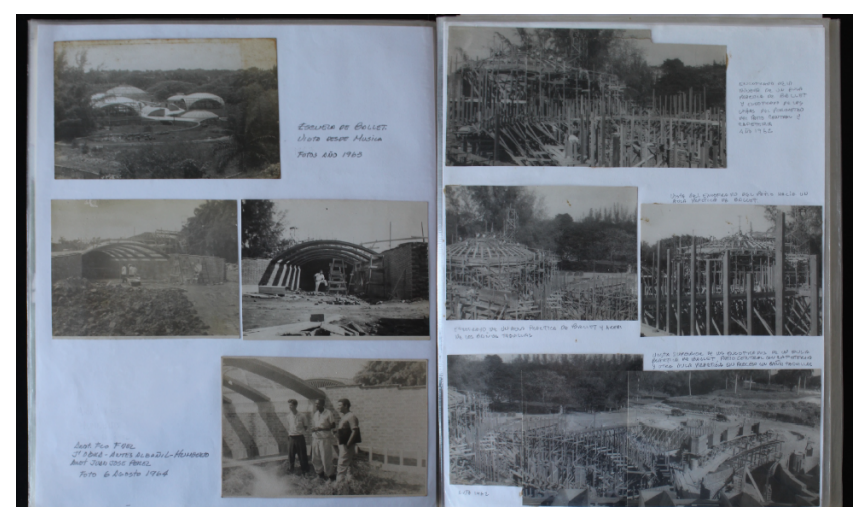

Figure 9. Example page of primary construction documents.

\section{CONCLUSIONS}

The VT/IM approach is a method for preliminary documentation and communication. This method is an efficient choice if the building or area to be documented cannot be captured using 2D methods and a 3D model is not appropriate for the needs of the project. This method fills the void of current methods such as 2D digital mapping and laser scanning depicted in Fig. 3. In our case study, since a photogrammetry model or laser scan model was outside the scope of the project's needs, budget, and time constraints, the VT/IM approach was efficient in terms of time, cost, and data management. The VT/IM method can be used and adopted for future conservation and analysis projects to aid users in conveying and understanding conservation problems in 3D.

\section{ACKNOWLEDGEMENTS}

We are very grateful to the following architects and builder of the National Art Schools for sharing their time, stories, and information with us: Roberto Gottardi, Vittorio Garatti, and Jose Moquera. Additionally we are thankful to the following Princeton persons and institutions for their financial support: Ruben Gallo and Gabriella Nouzeilles (Program in Latin American Studies), Anastasia Vracnos (Vice Provost for International Affairs and Operations, funding source is Banco Santander through the Learning Across Boarders (LABs) program), Emily Carter and Antoine Kahn (School of Engineering and Applied Science), 
James Smith (Department of Civil and Environmental Engineering), and Naomi Leonard (Council on Science and Technology). Finally, we are thankful to the National Science Foundation for their support of this research.

\section{DISCLAIMER}

This material is based upon work supported by the National Science Foundation Graduate Research Fellowship Program under Grant No. DGE-1656466. Any opinions, findings, and conclusions or recommendations expressed in this material are those of the author(s) and do not necessarily reflect the views of the National Science Foundation."

Copyright: (c) SPOT Image Copyright 2017 , Isabella Douglas. (c) SPOT Image Copyright 2017, Rebecca Napolitano.

\section{References}

Addison, A. C., 2000. Emerging trends in virtual heritage. IEEE Multimedia 7(2), pp. 22-25.

Bruno, F., Bruno, S., De Sensi, G., Luchi, M.-L., Mancuso, S. and Muzzupappa, M., 2010. From 3D reconstruction to virtual reality: A complete methodology for digital archaeological exhibition. Journal of Cultural Heritage 11(1), pp. 42-49.

Douglas, I., 2017. Cuba's national school of ballet: Redefining a structural icon. Thesis.

Hou, L., Wang, Y., Wang, X., Maynard, N., Cameron, I., Zhang, S. and Maynard, Y., 2014. Combining Photogrammetry and Augmented Reality Towards an Integrated Facility Management System for the Oil Industry. Proceedings of the IEEE 102(2), pp. 204-220.

Koehl, M. and Brigand, N., 2012. Combination of virtual tours, 3D model and digital data in a 3D archaeological knowledge and information system. ISPRS - International Archives of the Photogrammetry, Remote Sensing and Spatial Information Sciences XXXIX-B4(September), pp. 439-444.

Koehl, M., Schneider, A., Fritsch, E., Fritsch, F., Rachedi, A. and Guillemin, S., 2013. Documentation of historical building via virtual tour: the complex building of baths in strasbourg. ISPRS - International Archives of the Photogrammetry, Remote Sensing and Spatial Information Sciences XL5/W2(September), pp. 385-390.

Letellier, R., 2007. Recording, Documentation, and Information Management for the Conservation of Heritage Places: Guiding Principles. Getty Conservation Institute.

Loomis, J. A., 1999. Revolution of forms: Cuba's forgotten art schools. Princeton Architectural Press.

Mount Vernon Virtual Tour, 2016. http://www.mountvernon.org/site/virtual-tour/.

Website,

National Art School, $2016 . \quad$ Website, https://www.wmf.org/project/national-art-schools.

National Schools of Art: Cubanacan, n.d.

Paolini, P., Simonetti, F. A., Forti, G. and Corrao, A., 2014. Digital Aléria: Multiresolution Technologies Arming International Collaboration to Restore the Past and Restart. Heritage in the Digital Era 3(1), pp. 215-236.

Tour the Town, 2012. Website, http://tour.history.org/. 